BMJ Open Diabetes

Research \& Care

\title{
Custom-made footwear designed for indoor use increases short-term and long-term adherence in people with diabetes at high ulcer risk
}

Renske Keukenkamp (D) , Jaap J van Netten (D) , Tessa E Busch-Westbroek, Sicco A Bus (1)

\section{ABSTRACT}

Introduction To explore changes in footwear adherence following provision of custom-made indoor footwear in people with diabetes at high risk for plantar foot ulceration and in possession of regular custom-made footwear. Research design and methods Adherence indoors and outdoors was assessed objectively as percentage of steps custom-made footwear was worn, at baseline (in regular custom-made footwear), and at 1 and 12 months after providing custom-made indoor footwear (in both indoor and regular footwear). Primary group: participants with low $(<80 \%)$ baseline indoor adherence; secondary group: participants with high ( $\geq 80 \%)$ baseline indoor adherence. Peak plantar pressures of the indoor footwear were compared with the regular custom-made footwear. Footwear usability was evaluated at 3 months via a questionnaire. At 12 months, ulcer recurrence was assessed through participant/prescriber reporting. Results 0 f 31 participants, 23 had low baseline indoor adherence $(<80 \%)$. Overall adherence in this group increased statistically significant from median 65\% (IQR: $56 \%-72 \%)$ at baseline to $77 \%(60 \%-89 \%)$ at 1 month $(p=0.002)$ and $87 \%(60 \%-93 \%)$ at 12 months $(p<0.001)$. This was due to a significant increase in adherence indoors: baseline: $48 \%$ (21\%-63\%); 1 month: $71 \%$ $(50 \%-83 \%)(p=0.001)$; and 12 months: $77 \%(40 \%-91 \%)$ $(p<0.001)$. Mean peak plantar pressures were comparable between the indoor and regular custom-made footwear. Participants were positive about usability. One-year ulcer recurrence rate was $26 \%$.

Conclusions Footwear adherence increased in the shortterm and long-term after provision of custom-made indoor footwear in people at high risk of diabetic foot ulceration with low baseline adherence, because they actively wore their newly provided indoor footwear inside their house. Footwear adherence may be helped by using both regular and indoor custom-made footwear in clinical practice; the effect on ulcer recurrence should be investigated in future trials.

Department of Rehabilitation Medicine, Amsterdam UMC, University of Amsterdam, Amsterdam Movement Sciences, Amsterdam UMC, Amsterdam, The Netherlands

Correspondence to Dr Sicco A Bus; s.a.bus@amsterdamumc.nl

\section{Significance of this study}

What is already known about this subject?

- Custom-made footwear is effective in ulcer prevention, but adherence is low indoors.

What are the new findings?

- Footwear adherence increased significantly in shortterm and long-term after provision of custom-made indoor footwear in low-adherent participants.

- Footwear adherence remained high in high-adherent participants, with substantial use of the indoor footwear.

- Participants were generally satisfied with their custom-made indoor footwear, and scored most usability aspects positively.

- One-year ulcer recurrence rate was $26 \%$.

How might these results change the focus of research or clinical practice?

- A combination of regular and indoor custom-made footwear is a useful intervention to increase adherence, and its implementation is recommended.

has healed, recurrence within 1 year is around $40 \%$ and $60 \%$ within 3 years. ${ }^{1}$ Due to this high risk of foot ulceration and its recurrence, its prevention is of fundamental importance.

Custom-made footwear is an effective intervention to help prevent foot ulceration ${ }^{23}$ and is recommended in international guidelines. ${ }^{4}$ The aim of such footwear is to reduce ulcer risk by redistributing and lowering mechanical stress at high-risk regions and providing a proper fit. ${ }^{4}$ For footwear to achieve this, it needs to be worn. ${ }^{56}$ However, adherence to wearing custom-made footwear is a challenge in people with diabetes at high ulcer risk, and they frequently wear footwear that is not protective or go barefoot (or in socks only) when weight-bearing. ${ }^{458}$ Adherence is particularly low indoors, while approximately $60 \%$ of their daily steps are taken indoors. ${ }^{9-11}$ 
Interventions to specifically increase footwear adherence indoors are needed for this high-risk population. ${ }^{5}$

Research on adherence-increasing interventions, however, is limited; a recent systematic review found only one study that attempted to increase footwear adherence by using motivational interviewing. ${ }^{12}$ This resulted in some improvement in footwear adherence 1 week after motivational interviewing, but a return of adherence to baseline levels after 3 months, with especially low adherence indoors. ${ }^{9}$ Participants provided various reasons for their low indoor adherence, such as the weight of the footwear, difficulties with donning and doffing and difficulties moving around inside the house with their custom-made footwear. ${ }^{9}$ Custom-made footwear specifically designed for indoor use might overcome these drawbacks and improve adherence.

We developed custom-made indoor footwear based on an evaluation of needs and preferences of people with diabetes and on a set of design rules such footwear should fulfil. ${ }^{13}$ The most important was similar offloading efficacy compared with a person's regular custom-made footwear, ${ }^{13}$ because indoor footwear may improve adherence by increasing wearing time indoors andcan replace time that regular custom-made footwear would otherwise be worn. We aimed to explore the short-term and longterm changes in footwear adherence following the provision of such custom-made indoor footwear in people with diabetes at high risk of foot ulceration and regular custom-made footwear.

\section{RESEARCH DESIGNS AND METHODS}

\section{Study design and setting}

A prospective non-controlled intervention study (prepost design) in three multidisciplinary diabetic foot outpatient clinics.

\section{Participants}

Inclusion criteria were: type 1 or 2 diabetes mellitus; moderate to high risk for foot ulceration (International Working Group on the Diabetic Foot risk 2 or 3$)^{4}$; and in possession of custom-made footwear (ie, custommade insoles worn in custom-made footwear). Exclusion criteria were: presence of a foot ulcer; Charcot foot deformation or active Charcot's neuroarthropathy; amputation at or beyond the tarsometatarsal level; necessity to wear high-cut footwear (midtibia level or higher) at all times; and inability to walk unaided. Participants who took part in a preceding survey to assess needs and expectations regarding custom-made indoor footwear and expressed a need for such footwear were invited. ${ }^{13}$ Written informed consent was obtained from all participants prior to inclusion.

\section{Custom-made footwear}

Prior to the study, all participants possessed custom-made footwear that was prescribed by a rehabilitation medicine specialist and manufactured by a certified pedorthist from each of the three participating multidisciplinary clinics. The footwear consisted of custom-made insoles worn in custom-made shoes, both handmade from a positive last of the foot. The shoe had rocker profile outsoles and multidensity insoles with pressure relieving elements. ${ }^{14}$ This custom-made footwear is from here onwards referred to as 'regular footwear'.

\section{Custom-made indoor footwear}

During the study, participants were provided with custommade footwear specifically intended for indoor use (referred to as 'indoor footwear' from here onwards), in addition to their regular custom-made footwear. To ensure the same biomechanical offloading capacity as the regular footwear, the indoor footwear (online supplemental figure S1) was built on the same shoe last, was ankle-high (ie, above ankle but below midtibia level) and was fitted with a custom-made insole similar to the insole used in the regular footwear. ${ }^{13}$ This similarity in offloading capacity was the key characteristic as determined in our pilot study, ${ }^{13}$ because people may replace wearing of their regular footwear inside their house with wearing the indoor footwear. To maintain an optimal biomechanical environment, similarity in offloading between regular and indoor footwear is important, and this was objectively assessed (see sections 'Procedures' and 'In-shoe plantar pressure measurements' for more information). To facilitate usability, the shoe outsole was a lightweight material, the vamp was made of either microfiber (online supplemental figure S1 Type A), or felt (online supplemental figure S1 Type B) and held together with a combination of leather, Velcro fastener and a zipper. Prior to the start of the study, participants were informed that the indoor footwear would be provided free of charge.

\section{Procedures}

On study entry, demographic and disease-related data were collected. Loss of protective sensation was assessed with a $10 \mathrm{~g}$ Semmes-Weinstein monofilament, ${ }^{15}$ foot amputations were documented by clinical assessment, and photographs of the feet were taken. Baseline adherence was determined by measuring step count with an activity monitor at the ankle and footwear use with a temperature sensor (see 'Adherence' section for details).

After this baseline visit, the indoor footwear was manufactured, and on its delivery, in-shoe plantar pressures were measured in both the participants' regular and indoor footwear (see 'In-shoe plantar pressure measurements' section for details). If necessary, the footwear was modified until peak pressures were similar between the two footwear types. ${ }^{4} 616$ One month after provision, adherence was again determined, now in the combination of regular and indoor footwear. At 3 months, a questionnaire was sent to the participants to evaluate: (1) usability, (2) satisfaction and (3) appearance of the indoor footwear and (4) the willingness to pay for the indoor footwear if prescribed in clinical practice. The questionnaire was based on the Monitor Orthopedic Shoes ${ }^{17}$ and 
consisted of questions scored on a 5-point Likert scale. The response options were combined to three categories: 'not or hardly present', 'neutral' and '(very much) present'. At 12 months, adherence was again determined in the combination of regular and indoor footwear. Any ulcer (recurrence) that had occurred in the previous 12 months was identified based on participant or pedorthist reports.

\section{Adherence}

Footwear adherence was determined by combining seven consecutive days of footwear use and daily step count measurements. Footwear use was measured with a small temperature-based sensor (@monitor, Department of Medical Technology and Innovation, Academic Medical Center, Amsterdam, The Netherlands), placed inside the custom-made footwear and recording temperature at 1 min intervals. The one or two pairs of footwear that were most frequently used, or three after provision of the indoor footwear, were provided with the @monitor. Simultaneously, daily step count was recorded with an activity monitor strapped above the ankle (StepWatch, Orthocare Innovations LLC, Oklahoma, USA). Participants were instructed to wear the StepWatch at all times, except when showering or bathing. Time spent outdoors, cycling and not wearing the StepWatch were logged by the participants in a report form.

Footwear use and daily step count were obtained for each measurement day and analyzed with custom-built software in Matlab R2018a (MathWorks, Natick, Massachusetts, USA). ${ }^{10}$ Only valid recordings (ie, a minimum of 4 days of combined step count and footwear use measured, including 1 weekend day) were included in analyses. ${ }^{18} 19$ Barefoot walking or walking in non-prescribed footwear was assumed when the StepWatch showed activity and the $@$ monitor did not show footwear usage. The daily activity $\log$ was used to differentiate between indoor and outdoor adherence. Adherence was defined as the percentage of steps while wearing prescribed footwear and calculated as the ratio between the cumulative number of steps with prescribed footwear worn and the total number of steps taken. 'Low indoor adherence' was defined as $<80 \%$ of the total steps indoors taken in prescribed footwear. ${ }^{6}$

\section{In-shoe plantar pressure measurements}

In-shoe peak plantar pressures were measured dynamically with the Pedar-X in-shoe pressure measurement system (Novel GmbH, Munich, Germany) at a $50 \mathrm{~Hz}$ sampling frequency. To increase generalizability, participants were asked to walk at a comfortable speed over a flat surfaced walkway. The first and last step of each walk were discarded. Plantar pressure data were collected over a minimum of 12 midgait steps per foot per condition, as determined to be valid and reliable. ${ }^{20}$ Pressures were analyzed with Novel multimask software (V.13.3.65). The mean peak pressures at eight anatomical foot regions were calculated for the left and right foot separately: the toes (hallux, dig 2-3 and dig 4-5), forefoot (metatarsal head 1, metatarsal head 2-3 and metatarsal head 4-5), midfoot and heel.

\section{Statistical analysis}

Patient characteristics, adherence, daily step count, total wearing time and in-shoe peak plantar pressures were summarized using descriptive statistics. Separate analyses were undertaken for participants with low indoor adherence $(<80 \%$, primary group) and high indoor adherence $(\geq 80 \%)$ at baseline. Independent samples t-tests and Fisher's exact tests were used to compare patient characteristics between low-adherence and high-adherence groups. Wilcoxon signed rank test was used to compare adherence, step count and wearing time between both follow-up moments and baseline. Paired sample t-test was used to compare in-shoe peak plantar pressures between indoor and regular custom-made footwear for the eight anatomical regions of both the left and right foot. A Bonferronicorrected significance level of $\mathrm{p}<0.025(0.05 / 2)$ was used for adherence and wearing time, as two primary analyses were done, and $\mathrm{p}<0.004(0.05 / 12)$ for peak plantar pressures. Wilcoxon effect sizes $(r)$ were calculated for adherence and wearing time as follows: $r=Z / \sqrt{ }(N)$. Statistical analyses were performed using SPSS V.26.0 (SPSS Inc). In case of missing adherence data at baseline, adherence was imputed using missing value analysis regression in SPSS, with wearing time as predictor. First observation carried backward was used to impute missing adherence data at 1 month and last observation carried forward for missing adherence data at 12 months follow-up. Data were not imputed in case of death.

\section{RESULTS}

\section{Participants}

Thirty-four participants completed baseline measurements; three dropped out during follow-up (figure 1). Twenty-three participants had low indoor adherence at baseline, and eight had high adherence (table 1). Of the 31 analyzed participants, 13 were female $(42 \%)$, mean (SD) age was 69.3 (9.9) years, and 24 had type 2 diabetes $(77 \%)$, with no difference between low-adherence and high-adherence groups (table 1).

\section{Missing data}

Adherence data were missing for three participants at baseline (equipment failure), three at 1 month (equipment failure, hospitalization and missed visit) and eight at 12 months follow-up (two equipment failure, one untraceable, and five missed visit). Analyses on the imputed dataset and on available cases provided similar results; we used the imputed dataset for reporting.

\section{Footwear adherence, wearing time, and step count}

In participants with low baseline adherence, overall adherence increased significantly from baseline (65\%) to 1 month (77\%; $\mathrm{p}=0.002 ; r=0.66$ ) and from baseline to 12 months $(87 \% ; \mathrm{p}<0.001 ; r=0.74$; table 2$)$. Adherence indoors increased significantly from $48 \%$ to $71 \%$ 


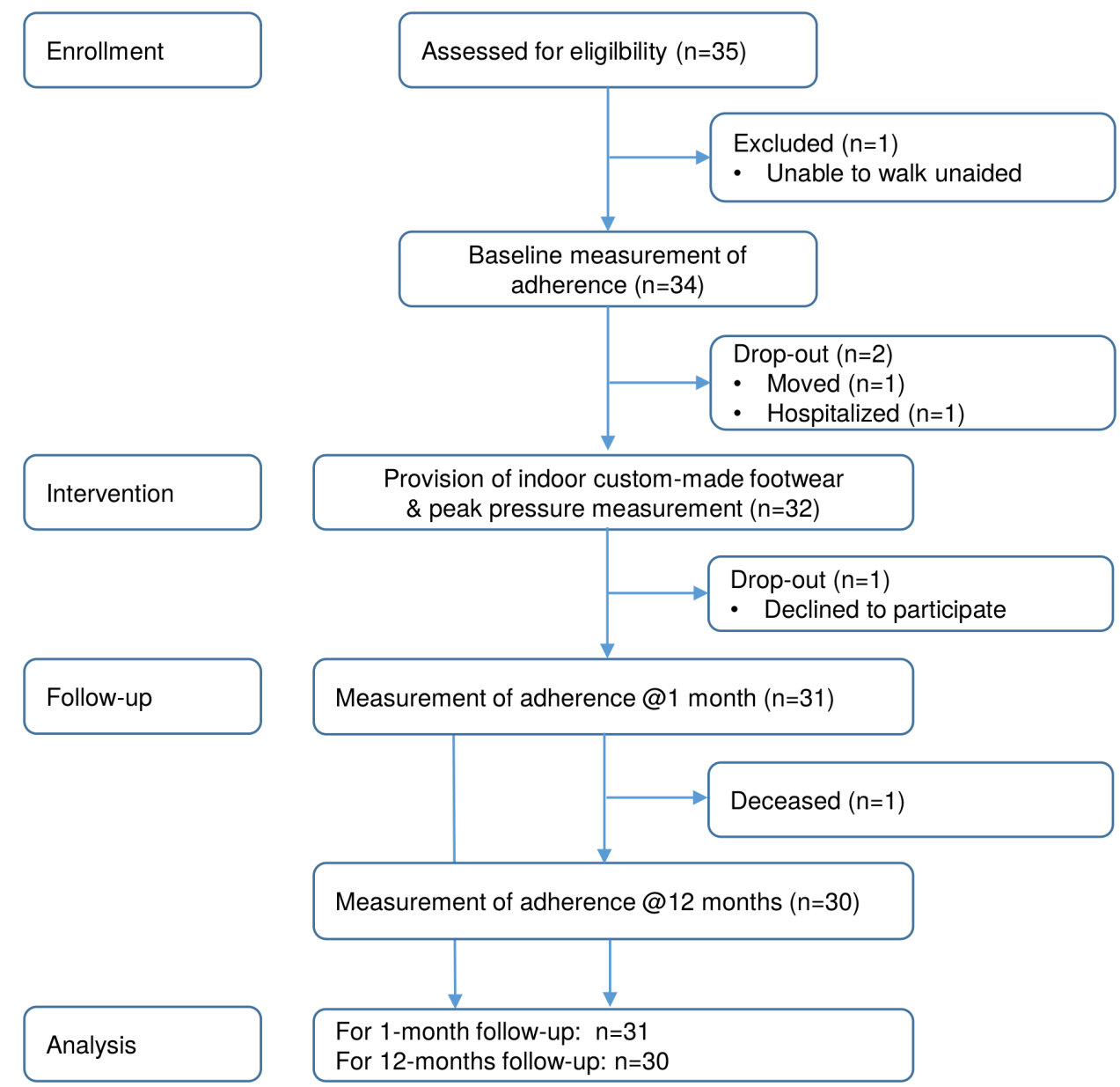

Figure 1 Flow diagram summarizing participants included and excluded from analysis.

$(\mathrm{p}=0.001 ; r=0.74)$ and $77 \%(\mathrm{p}<0.001 ; r=0.78)$, respectively. Adherence outdoors was high at baseline (94\%) and improved non-significantly to $98 \%$ and $99 \%$, respectively (table 2 ).
Ten of 23 participants (44\%) with low baseline adherence improved to high adherence ( $>80 \%$ of steps) at 1 month and 12 participants $(55 \%)$ at 12 months. Similar to adherence, time that custom-made footwear (indoor

Table 1 Participant characteristics

\begin{tabular}{lllll}
\hline & $\begin{array}{l}\text { Baseline indoor } \\
\text { adherence low } \\
(\mathbf{n = 2 3 )}\end{array}$ & $\begin{array}{l}\text { Baseline indoor } \\
\text { adherence high } \\
(\mathbf{n = 8 )}\end{array}$ & P value & $\begin{array}{l}\text { All participants } \\
(\mathbf{n}=\mathbf{3 1})\end{array}$ \\
\hline Age (years) & $68.3 \pm 11.2$ & $72.1 \pm 4.2$ & 0.357 & $69.3 \pm 9.9$ \\
\hline Female gender & $39(9)$ & $50(4)$ & 0.689 & $42(13)$ \\
\hline BMI $\left(\mathrm{kg} / \mathrm{m}^{2}\right)$ & $30 \pm 7$ & $32 \pm 8$ & 0.614 & $31 \pm 7$ \\
\hline Type 2 diabetes & $78(18)$ & $75(6)$ & 1.0 & $77(24)$ \\
\hline Diabetes duration (years) & $19.5 \pm 15.7$ & $19.5 \pm 10.2$ & 0.997 & $19.5 \pm 14.5$ \\
\hline LOPS, based on abnormal & $100(23)$ & $100(8)$ & - & $100(31)$ \\
monofilament perception & & & & \\
\hline Amputation† & $22(5)$ & $25(2)$ & 1.0 & $23(7)$ \\
\hline \multicolumn{1}{c}{ Digiti } & $(3)$ & $(2)$ & & $(5)$ \\
\hline Ray/Forefoot & $(2)$ & 0 & & $(2)$ \\
\hline
\end{tabular}

Data are expressed as mean $\pm S D$, or \% (n). No significant differences were found between the groups baseline indoor adherence 'low' and 'high'.

*Diabetes duration was available from $n=27$.

†Amputation up to tarsometatarsal level.

BMI, body mass index; LOPS, loss of protective sensation. 


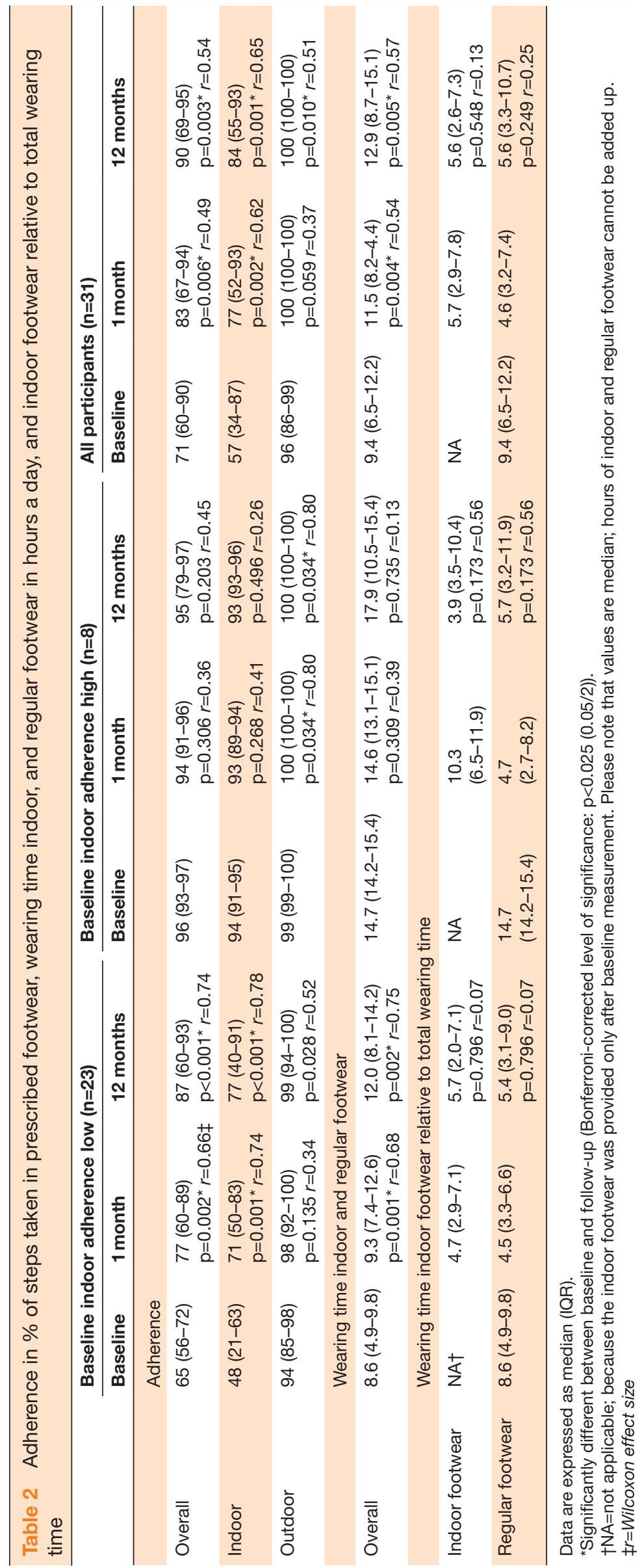


and regular) was worn increased significantly from 8.6 hours/day to 9.3 hours/day $(\mathrm{p}=0.0014 ; r=0.68)$ and 12.0 hours/day ( $\mathrm{p}=0.002 ; r=0.75$; table 2$)$, respectively. Wearing time at 1 and 12 months was evenly distributed between indoor and regular footwear (table 2).

In participants with high indoor adherence at baseline, both adherence (table 2) and wearing time (table 2) remained high. They wore the indoor footwear 10.3 hours/day at 1 month and 3.9 hours/day at 12 months.

All participants took more steps indoors compared with outdoors and had a non-significantly lower daily step count during follow-up compared with baseline (table 3). In participants with low baseline adherence, $59 \%$ of indoor steps were in the indoor footwear at 1 month and $45 \%$ at 12 months. In participants with high adherence at baseline, this was $81 \%$ and $45 \%$, respectively. The indoor footwear was hardly used outdoors (range: $0 \%-2 \%$ ).

\section{Peak plantar pressures}

Peak plantar pressures in all regions of the indoor footwear were comparable with the regular footwear (table 4). Peak pressures $>200 \mathrm{kPa}$ were less frequently present in indoor footwear (table 4).

\section{Usability of indoor footwear}

Response rate for the usability questionnaire was $90 \%$ $(\mathrm{n}=28)$. Most responders $(79 \%)$ were satisfied or very satisfied with the indoor footwear (table 5), and 68\% felt that it met their expectations. The indoor footwear was considered appealing by $43 \%$ of the respondents. All but one of the respondents reported negative usability aspects 'difficult to don and doff', 'too heavy', 'too tight fit' and 'skin irritation' as neutral or not or hardly present (table 5). The largest group of responders (36\%) were willing to pay between $€ 0$ and $€ 50$ for the indoor footwear and $32 \%$ between $€ 50$ and $€ 100$.

\section{Ulcer recurrence}

Eight of the 31 participants (26\%) developed a recurrent ulcer during follow-up, of which four had low indoor adherence at baseline. Seven out of eight ulcers were plantar, of which five in the forefoot and two locations unknown; one ulcer was dorsal, caused by skin getting caught in the zipper of the indoor footwear.

\section{DISCUSSION}

We assessed changes in footwear adherence after provision of custom-made indoor footwear in people with diabetes at high risk of foot ulceration and already in possession of regular custom-made footwear. People with low baseline indoor adherence significantly increased their adherence in the short-term and long-term after provision of indoor footwear, predominantly as a result of increasing their indoor adherence, as well as wearing time. Adherence remained high in people with high baseline indoor adherence; they wore their indoor footwear for substantial amounts of time in the short term and long term. Ulcer recurrence in 12 months was $26 \%$, with mostly plantar ulcers. The indoor footwear had similar offloading capacity as regular custom-made footwear, and almost all participants were satisfied with the indoor footwear and were neutral or positive about usability aspects. Custom-made indoor footwear in addition to regular custom-made footwear therefore seems a useful intervention to improve adherence to wearing prescribed footwear in people with diabetes at high risk of foot ulceration.

Adherence strongly improved both in the short term and long term from additionally providing a pair of custom-made indoor shoes. As expected, indoor adherence improved the most, because the intervention specifically targets indoor adherence, and because indoor adherence was lowest at baseline and therefore had most potential to increase. People with low adherence at baseline (ie, $<80 \%$ of steps indoors in protective footwear) showed absolute $23 \%$ and $29 \%$ improvements in adherence in the short term and long term, respectively. At 12 months, $55 \%$ of this group was highly adherent. Outdoor adherence was already high at baseline in this group,and remained high over time, showing that footwear adherence is not so much an issue outdoors. However, participants were clearly more active inside their homes compared with outside, even more than found in previous studies. ${ }^{9-11}$ This again stresses the importance of an intervention specifically targeting indoor adherence. In line with increased adherence, wearing time also increased. This suggests that the higher percentage of steps taken in protective footwear was the result of an increase in hours the footwear was worn.

Adherence and wearing time in participants with high baseline adherence remained high over time. Given the high baseline adherence of $96 \%$, little opportunity for increased adherence was possible for this group. Important, however, was that most steps indoors were taken in the indoor footwear at 1 month and still almost half at 12 months. This indicates that people with high adherence also benefit from the provision of indoor footwear and suggests that its provision should not be limited to those with low indoor adherence.

Almost all participants were satisfied with their indoor footwear, and most scored positive on usability aspects. Earlier research showed that difficulties with donning and doffing, as well as the weight of the footwear, are reasons for low indoor adherence. ${ }^{9}$ These usability aspects were considered in the indoor footwear design. The positive usability scores, in combination with the increased adherence, suggest a successful design of the indoor footwear for most people.

The ulcer recurrence rate was $26 \%$ in 12 months, lower than found in a review ${ }^{1}$ but still considerable given the increase in adherence. Although high footwear adherence combined with pressure-reducing footwear reduces the risk for plantar foot ulcer recurrence, ${ }^{6}$ it does not eliminate risk completely. The recurrence rate found in our study may be explained by the improved but still 


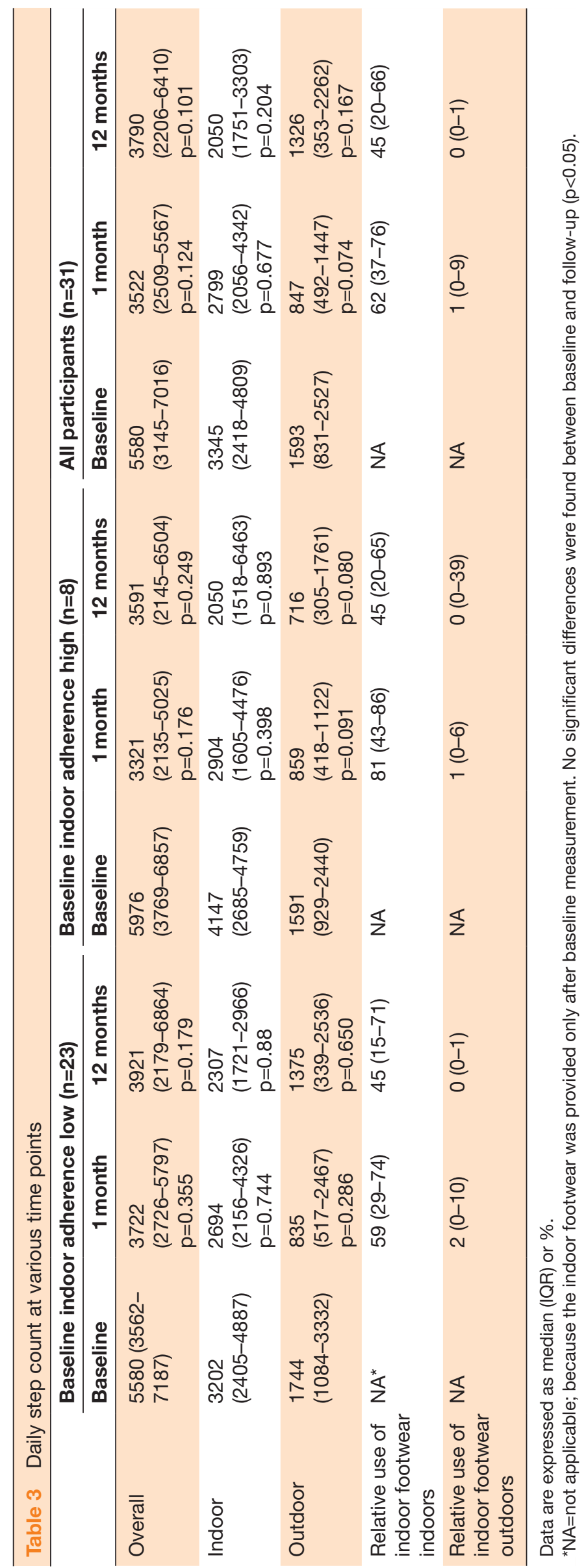




\begin{tabular}{|c|c|c|c|c|c|c|}
\hline & & Indoor footwear* & Regular footwear* & Mean difference $(95 \% \mathrm{Cl}) \dagger \ddagger$ & $\%$ difference & $P$ value \\
\hline \multirow[t]{2}{*}{ Hallux } & Left & $121 \pm 46$ & $122 \pm 53$ & $-1(-12$ to 11$)$ & -1 & 0.908 \\
\hline & Right & $124 \pm 47$ & $128 \pm 66$ & $-4(-18$ to 9$)$ & -3 & 0.525 \\
\hline \multirow[t]{2}{*}{ MTH1 } & Left & $141 \pm 40$ & $145 \pm 60$ & $-4(-21$ to 14$)$ & -3 & 0.653 \\
\hline & Right & $146 \pm 40$ & $153 \pm 72$ & $-8(-28$ to 13$)$ & -5 & 0.467 \\
\hline \multirow[t]{2}{*}{ MTH2-3 } & Left & $145 \pm 36$ & $151 \pm 56$ & $-6(-22$ to 10$)$ & -4 & 0.460 \\
\hline & Right & $157 \pm 43$ & $157 \pm 52$ & $-1(-13$ to 12$)$ & -1 & 0.916 \\
\hline \multirow[t]{2}{*}{ MTH4-5 } & Left & $121 \pm 39$ & $124 \pm 45$ & $-3(-15$ to 9$)$ & -2 & 0.599 \\
\hline & Right & $124 \pm 48$ & $123 \pm 52$ & $0(-9$ to 10$)$ & 0 & 0.972 \\
\hline \multirow[t]{2}{*}{ Midfoot } & Left & $117 \pm 38$ & $115 \pm 35$ & $2(-8$ to 12$)$ & 2 & 0.634 \\
\hline & Right & $112 \pm 29$ & $115 \pm 36$ & $-4(-12$ to 4$)$ & -3 & 0.343 \\
\hline \multirow[t]{2}{*}{ Heel } & Left & $187 \pm 52$ & $201 \pm 76$ & $-14(-33$ to 3$)$ & -7 & 0.112 \\
\hline & Right & $185 \pm 58$ & $209 \pm 69$ & $-24(-47$ to -1$)$ & -10 & 0.046 \\
\hline
\end{tabular}

${ }^{*}$ Data are provided as mean $\pm \mathrm{SD} \mathrm{kPa}$.

†Mean difference is peak pressure in indoor footwear minus custom-made footwear; a negative score means lower pressures in the indoor footwear.

$\ddagger$ No significant differences were found between indoor and regular footwear (Bonferroni-corrected level of significance: $p<0.004(0.05 / 12)$ ). MTH, metatarsal head.

not optimal adherence in some cases. For people at high risk, every step without protection may be one too much. Second, the target peak pressure of $200 \mathrm{kPa}^{62122}$ used in the design of the indoor footwear may still be too high for some people, for instance in case of ample weight-bearing

Table 5 Satisfaction and usability characteristics of participants' indoor footwear

\begin{tabular}{|c|c|c|c|}
\hline $\begin{array}{l}\text { Overall } \\
\text { satisfaction }\end{array}$ & $\begin{array}{l}\text { (Very) } \\
\text { unsatisfied }\end{array}$ & Neutral & $\begin{array}{l}\text { (Very) } \\
\text { satisfied }\end{array}$ \\
\hline & $7(2)$ & $14(4)$ & $79(22)$ \\
\hline $\begin{array}{l}\text { Positive usability } \\
\text { characteristics }\end{array}$ & $\begin{array}{l}\text { Not or hardly } \\
\text { present }\end{array}$ & Neutral & $\begin{array}{l}\text { (Very } \\
\text { much) } \\
\text { present }\end{array}$ \\
\hline Good durability & - & $50(14)$ & $50(14)$ \\
\hline Easy maintenance & $10(3)$ & $29(8)$ & $61(17)$ \\
\hline Appealing footwear & - & $57(16)$ & $43(12)$ \\
\hline $\begin{array}{l}\text { Negative usability } \\
\text { characteristics }\end{array}$ & $\begin{array}{l}\text { Not or hardly } \\
\text { present }\end{array}$ & Neutral & $\begin{array}{l}\text { (Very } \\
\text { much) } \\
\text { present }\end{array}$ \\
\hline $\begin{array}{l}\text { Too much } \\
\text { sweating }^{*}\end{array}$ & $85(22)$ & $15(4)$ & - \\
\hline Too heavy* & $88(23)$ & $8(2)$ & $4(1)$ \\
\hline Cold feet $†$ & $89(24)$ & $11(3)$ & - \\
\hline $\begin{array}{l}\text { Difficult to donn } \\
\text { and doff }\end{array}$ & $89(25)$ & $7(2)$ & $4(1)$ \\
\hline Too tight fit† & $93(25)$ & $4(1)$ & $4(1)$ \\
\hline Ulceration† & $93(25)$ & $4(1)$ & $4(1)$ \\
\hline Skin irritation† & $93(25)$ & $4(1)$ & $4(1)$ \\
\hline
\end{tabular}

Data expressed as \% (n) of responders.

*Missing data $\mathrm{n}=2$.

†Missing data $\mathrm{n}=1$. activity, resulting in excessive plantar cumulative tissue stress. ${ }^{23}{ }^{24}$ Although our results suggest that indoor footwear potentially may help in ulcer prevention, its effectiveness should be assessed in a randomized controlled trial (RCT) with ulcer recurrence as a primary outcome. However, as indoor footwear in itself may not be enough to remove all barriers in ulcer prevention, this intervention should preferably be combined with additional preventative interventions as part of an RCT using a personalized treatment approach for ulcer prevention. ${ }^{25}$

A strength of the present study was the objective measurement of footwear adherence, as recommended for diabetic foot disease research..$^{26}$ While this might affect adherence due to participants' awareness of being monitored, ${ }^{27}$ such an effect would be similar for baseline and follow-up measurements, and there is therefore no reason to assume that the improvement in adherence was caused by something other than the intervention. Another strength was that adherence was assessed in both the short term and the long term, providing a more valid and robust outcome. The lack of a control group not receiving indoor footwear or a control group with off-the-shelf footwear could be seen as a study limitation. However, we aimed to explore the effect of the intervention on adherence, for which a pre-post design is suitable. Nevertheless, we recommend to include a control group in future trials with this intervention. A limitation was how foot ulcer recurrence was assessed. Being a secondary outcome, full details and independent outcome assessment of ulcers were not obtained. While this limits interpretation regarding ulcer severity, the current finding of $26 \%$ ulcer recurrence is a useful indication of the potential effect of this single intervention on ulcer recurrence and can be used for power calculations to inform 
future RCTs. Finally, we had to deal with missing data, with equipment failure one of the main causes. However, we estimate a limited effect of missing data, as we could use wearing time for imputation, which is strongly related to adherence, ${ }^{10}$ and because the imputed data analysis showed similar results to analysis of the non-imputed data.

This is the first study that explored the effect of providing custom-made indoor footwear in addition to regular footwear on footwear adherence. Even though adherence was still low in some participants and many of them did not take every step indoors with the prescribed footwear, the results do suggest that the provision of indoor footwear in addition to regular footwear can be a useful intervention in daily practice for people with diabetes at high risk of ulceration. With costs being higher than participants are willing to pay, reimbursement is required.

\section{CONCLUSIONS}

Adherence to wearing custom-made footwear increased in the short term and long term after provision of custommade indoor footwear with adequate offloading properties for people at high-risk of diabetic foot ulceration. This was because they wore their custom-made indoor footwear inside their house and positively assessed its usability. Due to the substantially improved adherence, the combination of wearing custom-made indoor and regular footwear produces a more continuous lowpressure environment for the foot at risk. Implementation of this intervention may have a positive effect on ulcer recurrence, but this should be investigated in future trials.

Contributors RK collected the data, conducted the statistical analysis, interpreted the data and wrote the manuscript. JJvN contributed to data collection and statistical analysis. JJvN, TEB-W and SAB interpreted the data, reviewed and edited the manuscript. All authors approved the final manuscript. $S A B$ is the guarantor of the study and takes responsibility for the contents of the article.

Funding This study was supported by funds from CZ Zorgverzekering and Ontwikkelings Fonds Orthopedisch Schoentechnici (OFOM). The funders had no role in study design, data collection and analysis, decision to publish, or preparation of the manuscript.

\section{Competing interests None declared.}

\section{Patient consent for publication Not applicable.}

Ethics approval This study involves human participants, but the Medical Ethics Review Committee of the Amsterdam University Medical Center waived the requirement for ethical review under the Medical Research Involving Human Subjects Act (WM0) (W17_405\#17.474). Participants gave informed consent to participate in the study before taking part.

Provenance and peer review Not commissioned; externally peer reviewed.

Data availability statement Data are available on reasonable request.

Supplemental material This content has been supplied by the author(s). It has not been vetted by BMJ Publishing Group Limited (BMJ) and may not have been peer-reviewed. Any opinions or recommendations discussed are solely those of the author(s) and are not endorsed by BMJ. BMJ disclaims all liability and responsibility arising from any reliance placed on the content. Where the content includes any translated material, BMJ does not warrant the accuracy and reliability of the translations (including but not limited to local regulations, clinical guidelines, terminology, drug names and drug dosages), and is not responsible for any error and/or omissions arising from translation and adaptation or otherwise.

Open access This is an open access article distributed in accordance with the Creative Commons Attribution Non Commercial (CC BY-NC 4.0) license, which permits others to distribute, remix, adapt, build upon this work non-commercially, and license their derivative works on different terms, provided the original work is properly cited, appropriate credit is given, any changes made indicated, and the use is non-commercial. See: http://creativecommons.org/licenses/by-nc/4.0/.

ORCID iDs

Renske Keukenkamp http://orcid.org/0000-0001-7418-0778

Jaap J van Netten http://orcid.org/0000-0002-6420-6046

Sicco A Bus http://orcid.org/0000-0002-8357-9163

\section{REFERENCES}

1 Armstrong DG, Boulton AJM, Bus SA. Diabetic foot ulcers and their recurrence. N Engl J Med 2017;376:2367-75.

2 Crawford F, Nicolson DJ, Amanna AE, et al. Preventing foot ulceration in diabetes: systematic review and meta-analyses of RCT data. Diabetologia 2020;63:49-64.

3 Netten JJ, Raspovic A, Lavery LA, et al. Prevention of foot ulcers in the at-risk patient with diabetes: a systematic review. Diabetes Metab Res Rev 2020;36:e3270.

4 Bus SA, Lavery LA, Monteiro-Soares M, et al. Guidelines on the prevention of foot ulcers in persons with diabetes (IWGDF 2019 update). Diabetes Metab Res Rev 2020;36 Suppl 1:e3269.

5 van Netten JJ, Raspovic A, Lavery LA, et al. Prevention of foot ulcers in the at-risk patient with diabetes: a systematic review. Diabetes Metab Res Rev 2020;36 Suppl 1:e3270.

6 Bus SA, Waaijman R, Arts M, et al. Effect of custom-made footwear on foot ulcer recurrence in diabetes: a multicenter randomized controlled trial. Diabetes Care 2013;36:4109-16.

7 Bus SA, van Netten JJ. A shift in priority in diabetic foot care and research: $75 \%$ of foot ulcers are preventable. Diabetes Metab Res Rev 2016;32 Suppl 1:195-200.

8 Armstrong DG, Lavery LA, Kimbriel HR, et al. Activity patterns of patients with diabetic foot ulceration: patients with active ulceration may not adhere to a standard pressure off-loading regimen. Diabetes Care 2003;26:2595-7.

9 Keukenkamp R, Merkx MJ, Busch-Westbroek TE, et al. An explorative study on the efficacy and feasibility of the use of motivational interviewing to improve footwear adherence in persons with diabetes at high risk for foot ulceration. J Am Podiatr Med Assoc 2018;108:90-9.

10 Waaijman R, Keukenkamp R, de Haart M, et al. Adherence to wearing prescription custom-made footwear in patients with diabetes at high risk for plantar foot ulceration. Diabetes Care 2013;36:1613-8.

11 Armstrong DG, Abu-Rumman PL, Nixon BP, et al. Continuous activity monitoring in persons at high risk for diabetes-related lowerextremity amputation. J Am Podiatr Med Assoc 2001;91:451-5.

12 van Netten JJ, Sacco ICN, Lavery LA, et al. Treatment of modifiable risk factors for foot ulceration in persons with diabetes: a systematic review. Diabetes Metab Res Rev 2020;36 Suppl 1:e3271.

13 Busch-Westbroek TE, Keukenkamp R, van Netten JJ. Users' needs and expectations and the design of a new custom-made indoor footwear solution for people with diabetes at risk of foot ulceration. Disability and Rehabilitation.

14 Bus SA, Zwaferink JB, Dahmen R, et al. State of the art design protocol for custom made footwear for people with diabetes and peripheral neuropathy. Diabetes Metab Res Rev 2020;36 Suppl 1:e3237.

15 van Netten JJ, Bus SA, Apelqvist J, et al. Definitions and criteria for diabetic foot disease. Diabetes Metab Res Rev 2020;36 Suppl 1:e3268.

16 Waaijman R, Arts MLJ, Haspels R, et al. Pressure-reduction and preservation in custom-made footwear of patients with diabetes and a history of plantar ulceration. Diabet Med 2012;29:1542-9.

17 van Netten JJ, Hijmans JM, Jannink MJA, et al. Development and reproducibility of a short questionnaire to measure use and usability of custom-made orthopaedic shoes. J Rehabil Med 2009;41:913-8.

18 Bus SA, Waaijman R, Nollet F. New monitoring technology to objectively assess adherence to prescribed footwear and assistive devices during ambulatory activity. Arch Phys Med Rehabil 2012;93:2075-9.

19 Coleman KL, Smith DG, Boone DA, et al. Step activity monitor: longterm, continuous recording of ambulatory function. J Rehabil Res Dev 1999;36:8-18. 
20 Arts MLJ, Bus SA. Twelve steps per foot are recommended for valid and reliable in-shoe plantar pressure data in neuropathic diabetic patients wearing custom made footwear. Clin Biomech 2011;26:880-4.

21 Owings TM, Apelqvist J, Stenström A, et al. Plantar pressures in diabetic patients with foot ulcers which have remained healed. Diabet Med 2009;26:1141-6.

22 Waaijman R, de Haart M, Arts MLJ, et al. Risk factors for plantar foot ulcer recurrence in neuropathic diabetic patients. Diabetes Care 2014;37:1697-705.

23 Lazzarini PA, Crews RT, van Netten JJ, et al. Measuring plantar tissue stress in people with diabetic peripheral neuropathy: a critical concept in diabetic foot management. J Diabetes Sci Technol 2019;13:869-80.

24 Hulshof CM, van Netten JJ, Pijnappels M, et al. The role of FootLoading factors and their associations with ulcer development and ulcer healing in people with diabetes: a systematic review. J Clin Med 2020;9. doi:10.3390/jcm9113591. [Epub ahead of print: 0711 2020].

25 Van Netten JJ, Woodburn J, Bus SA. The future for diabetic foot ulcer prevention: a paradigm shift from stratified healthcare towards personalized medicine. Diabetes Metab Res Rev 2020;36 Suppl $1: e 3234$.

26 Jeffcoate WJ, Bus SA, Game FL, et al. Reporting standards of studies and papers on the prevention and management of foot ulcers in diabetes: required details and markers of good quality. Lancet Diabetes Endocrinol 2016;4:781-8.

27 Lutjeboer T, van Netten JJ, Postema K, et al. Effect of awareness of being monitored on wearing of orthopaedic footwear. J Rehabil Med 2020;52:jrm00127. 